\title{
Evaluation of the Effect of Four Fibers on Laxation, Gastrointestinal Tolerance and Serum Markers in Healthy Humans
}

\author{
Maria L. Stewart ${ }^{\mathrm{a}}$ Soma D. Nikhanj ${ }^{\mathrm{a}}$ Derek A. Timm ${ }^{\mathrm{a}}$ William Thomas ${ }^{\mathrm{b}}$ \\ Joanne L. Slavin ${ }^{\text {a }}$ \\ ${ }^{a}$ Department of Food Science and Nutrition, University of Minnesota, St. Paul, Minn., and ${ }^{\text {b}}$ Division of Biostatistics, \\ School of Public Health, University of Minnesota, Minneapolis, Minn., USA
}

\section{Key Words}

Pullulan • Resistant starch • Short-chain fatty acids •

Gas production $\cdot$ Cholesterol $\cdot$ Ghrelin

\begin{abstract}
Background: Average dietary fiber intake in the United States is roughly half of the recommended amount. As new dietary fiber products are introduced to increase fiber intake, it is critical to evaluate the physiological effects of such fibers. Aims: This study examined the effect of 4 fibers derived from maize or tapioca on fecal chemistry, gastrointestinal (GI) symptoms and serum markers of chronic disease. Methods: Twenty healthy subjects completed the singleblind crossover study in which $12 \mathrm{~g}$ /day of fiber (pullulan, Promitor ${ }^{\mathrm{TM}}$ Resistant Starch, soluble fiber dextrin or Promitor Soluble Corn Fiber) or placebo (maltodextrin) were consumed for 14 days followed by a 21-day washout. Gl symptom surveys were completed (days 3 and 14), stools were collected (days 11-14), diet was recorded (days 12-14) and fasting blood samples were obtained (day 15). Results: The 4 test fibers were well tolerated, with mild to moderate $\mathrm{Gl}$ symptoms. Total short-chain fatty acid (SCFA) concentrations did not differ among the treatments. Fecal $\mathrm{pH}$ and in-
\end{abstract}

dividual SCFAs were affected by some treatments. Stool weight and serum markers of chronic disease did not change with these treatments. Conclusion: Increasing fiber intake by $12 \mathrm{~g} /$ day was well tolerated and may have a positive impact on colon health due to fermentation.

Copyright $\odot 2010$ S. Karger AG, Basel

\section{Introduction}

Dietary fiber confers a wide range of health effects, from alleviation of constipation to reduction of serum cholesterol $[1,2]$. The physiological effects of dietary fibers in humans depend on the physicochemical properties of the fiber, the gut microflora and the human gastrointestinal (GI) tract. Average fiber intake in the USA is $13-18 \mathrm{~g} / \mathrm{day}$, approximately half of the adequate intake of $25 \mathrm{~g} /$ day for women and $38 \mathrm{~g} /$ day for men $[3,4]$. Adequate intake of fiber was determined based on the amount of fiber required to reduce the risk of coronary heart disease $[3,4]$.

Fermentation of fiber promotes gut health by producing short-chain fatty acids (SCFAs) and stimulating GI bacteria growth. Acetate, propionate and butyrate are the

\section{KARGER}

(C) 2010 S. Karger AG, Basel

Fax +41613061234

E-Mail karger@karger.ch

www.karger.com
Accessible online at:

www.karger.com/anm
Joanne L. Slavin

1334 Eckles Avenue

St. Paul, MN 55108 (USA)

Tel. +1 612624 7234, Fax +1 6126255272

E-Mail jslavin@umn.edu 
Table 1. Summary of fiber and placebo nutritional composition

\begin{tabular}{lccccc}
\hline & Pullulan & $\begin{array}{l}\text { Resistant } \\
\text { Starch }\end{array}$ & $\begin{array}{l}\text { Soluble } \\
\text { fiber dextrin }\end{array}$ & $\begin{array}{l}\text { Soluble } \\
\text { Corn Fiber }\end{array}$ & $\begin{array}{l}\text { 10-DE malto- } \\
\text { dextrin (placebo) }\end{array}$ \\
\hline Dietary fiber, \% & 87.9 & 53.4 & 53.4 & 45 & 0 \\
Digestible carbohydrate, \% & 9.8 & 38.1 & 42.9 & 25.9 & 95 \\
Fat, \% & 0 & 0 & 0 & 0 & 0 \\
Protein, \% & 0 & 0 & 0 & 0 & 0 \\
Moisture, \% & 2.3 & 8.5 & 3.7 & 29.1 & 5 \\
Amount needed for 12 g of fiber, g & 13.65 & 22.46 & 22.49 & 26.65 & 12.63 \\
\hline
\end{tabular}

All data provided by Tate and Lyle. Dietary fiber analysis methods: pullulan and Resistant Starch, AOAC method 991.43; soluble fiber dextrin and Soluble Corn Fiber, AOAC method 2001.03.

3 most common SCFAs; however, isobutryate, valerate and isovalerate may also be detectable in small amounts. SCFAs are metabolized in the colonic epithelium as well as other organs and contribute approximately $10 \%$ of total energy intake from a Western diet [5].

Laxation describes symptoms of the lower GI tract including increased stool weight, increased stool water content, decreased GI transit time and diarrhea [6]. Stool consistency and stool weight are moderated by stool water content. Disappearance of small nondigested components via fermentation and absorption of SCFAs reduce the amount of water in the stool, thereby preventing diarrhea. Alternatively, increased biomass due to fermentation increases stool weight and alleviates constipation.

Increased dietary fiber intake is often associated with adverse GI symptoms such as excess gas production. Tolerance, in the context of dietary fiber, is a state in which unwanted symptoms of dietary fiber consumption are not present [7].

While many Americans should increase their dietary fiber intake, the type of dietary fiber must be carefully considered before it is incorporated into the diet in order to maximize tolerance. In vitro data indicate that 4 new types of fiber, namely pullulan, Promitor ${ }^{\mathrm{TM}}$ Resistant Starch (Resistant Starch), soluble fiber dextrin and Promitor Soluble Corn Fiber (Soluble Corn Fiber), are fermentable [8]. All 4 of these fibers are isolated glucose polymers, but vary with regard to their physicochemical properties.

The primary objectives of this study were to compare the effects of these 4 fibers on stool weight, stool $\mathrm{pH}$, fecal SCFA concentrations and GI symptoms in healthy humans. Secondary objectives were to assess the effect of these fibers on serum markers of chronic disease in healthy humans.

\section{Subjects and Methods}

\section{Subject Recruitment and Characteristics}

The study design and recruitment procedures were approved by the Institutional Review Board at the University of Minnesota. Thirty-two subjects were recruited through flyers posted at the University of Minnesota. Subjects completed a medical history screening questionnaire over the telephone to determine study eligibility. Eight subjects did not meet the requirements (high BMI, vegetarian, smoker), and 4 subjects qualified but declined participation in the study. Ten healthy men (values are means \pm SEM: age $32 \pm 5$ years; weight $76 \pm 2 \mathrm{~kg}$; BMI $24.3 \pm 0.7$ ) and 10 healthy women (values are means \pm SEM: age $38 \pm 4$ years; weight $69 \pm 2 \mathrm{~kg}$; BMI $26.0 \pm 1.4$ ) were enrolled and completed all 5 treatments. All subjects were nonsmoking, normotensive and normolipidemic. During the 3 months prior to enrollment in the study, all subjects had maintained a stable weight. During the 6 months prior to enrollment in the study, subjects had not received medication for any of the following conditions: hyperlipidemia, hypertension, inflammation or bacterial infection. Subjects did not have a history of digestive disease and were not taking fiber supplements or laxatives. All subjects had verbal and written English literacy. Eligible subjects attended a screening visit at the General Clinical Research Center (GCRC) at the University of Minnesota to obtain anthropometric measurements, verify the medical history screening questionnaire and receive study instructions and supplies.

\section{Treatment Material}

Five treatments were administered during the study: 4 test fibers (pullulan, Resistant Starch, soluble fiber dextrin, Soluble Corn Fiber) and placebo (maltodextrin). All test products were provided by Tate and Lyle Inc. (Decatur, Ill., USA). Table 1 shows the composition of each fiber and the placebo. Pullulan is formed via the fermentation of dextrin by Aureobasidium pullulans to produce pullulan (average degree of polymerization 3,000; molecular weight 486,000$)$. $\alpha(1,4)$ linkages predominate, but $\alpha(1,6)$ linkages are also present, leading to decreased digestibility. The Resistant Starch used in this study is an RS3 type of resistant starch (RS; retrograded starch) produced from heat-moisturetreated high-amylose maize starch. Soluble fiber dextrin is a purified dextrin product derived from tapioca starch with an average 
degree of polymerization of 40 . Soluble Corn Fiber has an average degree of polymerization of 10 and is produced via corn starch hydrolysis. Soluble fiber dextrin and Soluble Corn Fiber contain a mixture of $\alpha-1,4, \alpha-1,6, \alpha-1,2$ and $\alpha-1,3$ glycosidic linkages. The placebo was a fully digestible maltodextrin preparation of $10 \mathrm{dex}-$ trose equivalents. All treatment materials were analyzed as dietary fiber by AOAC method 991.43 or AOAC method 2001.03 (table 1). Dietary fiber analyses were provided by Tate and Lyle Inc.

Subjects consumed their habitual diets and maintained their usual exercise pattern throughout the study. The treatment consisted of $12 \mathrm{~g}$ of dietary fiber or placebo per day, divided into two 6-gram doses, each mixed into $177 \mathrm{ml}$ of Musselman's Lite Apple Sauce (commercially available single-serving size, provided by study staff). Subjects consumed the fiber or placebo with apple sauce as a snack or with any meal throughout the day and were instructed to consume the 2 doses at least $1 \mathrm{~h}$ apart. Subjects returned any uneaten portions of apple sauce and fiber to assess compliance.

\section{Study Design}

Subjects consumed all 5 treatments in a single-blind crossover design with treatment periods of 14 days followed by a 21-day washout period. Four unique $5 \times 5$ Latin squares were used to assign treatment orders to subjects. Subjects collected all stools passed from day 11 until day 14. The Commode Specimen Collection Kit (Sage Products, Crystal Lake, Ill., USA) and sample collection bags with instructions were provided by the study staff. Subjects delivered samples on regular ice as soon as possible to the GCRC. Subjects were instructed by a registered dietitian to complete a 3-day food record on days 12-14 of the treatment period. On day 15 , subjects arrived fasted ( $12 \mathrm{~h}$ ) at the GCRC for anthropometric and vital sign measurements and blood draws. Subjects scheduled their next intervention and study visit and were provided with fiber or placebo, apple sauce, new questionnaires and food record and stool sample collection bags at this time.

\section{Assessment of Habitual Diet}

Food records were analyzed with the Nutrition Data System for Research (version 2006; University of Minnesota, Minneapolis, Minn., USA) for total energy, macronutrient and fiber intake per day. Water, fiber treatment or placebo, and apple sauce were not included in the diet analysis.

\section{Assessment of Laxation and Fecal Chemistry}

Laxation was assessed by subject surveys and by counting and evaluating the stools passed on days 11-14 of the treatment period. The following data were collected on days 3 and 14 via survey: (1) number of stools passed on that day and (2) consistency of stools passed on that day. Consistency of stools was rated on a 10 point scale $(1=$ diarrhea, $10=$ hard $)$.

The wet weight of the stool was determined in grams by weighing the collection bag on a balance and subtracting the weight of an average collection bag. Stool consistency was determined subjectively by laboratory workers based on the King's Stool Chart [9].

Subjects completed the GI symptoms survey on days 3 and 14 of each treatment period, rating the following symptoms: flatulence, bloating, cramps and stomach noises. Symptoms were rated on a 10 -point scale $(1=$ minimal, $10=$ excessive $)$.
Individual fecal samples (frozen at $-20^{\circ} \mathrm{C}$ until analysis) were analyzed for wet weight and stool consistency. Fecal samples from the 4-day collection period were pooled for each subject. Fecal pH was determined in an aliquot from the homogenized samples with a glass electrode at $25^{\circ} \mathrm{C}$ (Orion PerpHecT LogR meter, model 350; Thermo Electron Corporation, Beverly, Mass., USA).

Acetate, propionate, butyrate and total SCFAs were extracted, and concentrations were determined by gas chromatography [10]. Briefly, $200 \mathrm{mg}$ of stool was suspended in $1.6 \mathrm{ml}$ of distilled water. Sulfuric acid $(0.4 \mathrm{ml}, 50 \%)$ and diethyl ether $(2 \mathrm{ml})$ were added. Ethyl butyrate was added as the internal standard $(2 \mu \mathrm{l})$. Samples were mixed at room temperature in an orbital shaker for $45 \mathrm{~min}$ and centrifuged at 3,000 rpm for $5 \mathrm{~min}$. The supernatant was transferred and residual water was absorbed with calcium chloride. Samples were filtered using Gelman Acrodisc syringe filters $(13 \mathrm{~mm}$, pore diameter $0.25 \mu \mathrm{m})$ and immediately analyzed via gas chromatography. Analysis was conducted with a Stabilwax DA column (30 m, $0.53 \mathrm{~mm}$ internal diameter, $1-\mu \mathrm{m}$ film thickness; Restek, Bellefonte, Pa., USA). Helium was used as the carrier gas $(24 \mathrm{ml} / \mathrm{min})$. Hydrogen and air flow rates were 34 and 410 $\mathrm{ml} / \mathrm{min}$, respectively. Oven temperature was maintained at $90^{\circ} \mathrm{C}$ for $2 \mathrm{~min}$ and then increased to $120^{\circ} \mathrm{C}$ at $60^{\circ} \mathrm{C}$ per minute. Inlet temperature was $200^{\circ} \mathrm{C}$ and detector temperature was $200^{\circ} \mathrm{C}$.

\section{Assessment of Serum Markers of Chronic Disease}

Total cholesterol, high-density lipoprotein (HDL) cholesterol, low-density lipoprotein (LDL) cholesterol, total triglycerides, glucose, insulin and C-reactive protein were measured by Quest Diagnostics Inc. (Wooddale, Ill., USA). Blood samples for ghrelin analysis were collected in EDTA-coated Vacutainer ${ }^{\circledR}$ serum separator tubes prepared with $50 \mu \mathrm{l}$ of aprotinin solution $(0.9 \% \mathrm{NaCl}$, $0.9 \%$ benzyl alcohol, 500 Trypsin Inhibitory Units (TIU) of aprotinin) and frozen at $-70^{\circ} \mathrm{C}$ until analysis [11]. Ghrelin analysis was conducted using a radioimmunoassay kit (Linco Total Ghrelin RIA kit GHRT-89HK; Millipore Inc., Billerica, Mass., USA). All samples were run in triplicate.

\section{Assessment of Hunger}

Subjects completed hunger surveys on day 3 and day 14, in which they rated their hunger on a 10 -point scale $(1=$ no desire to eat, $10=$ unbearable hunger - must eat immediately)

\section{Data Analysis}

All data were analyzed with SAS (version 9; SAS Institute, Cary, N.C., USA). The mixed procedure was used to fit a general linear model for each outcome variable with a random intercept for each subject and terms for visit, carryover and gender. Gender and carryover were not significant in models for any measurement, so all analyses were conducted with male and female data pooled. Treatment means and standard errors, adjusted for visit, are presented. Statistical significance was set at $\mathrm{p}<0.05$.

\section{Results}

The subjects' ad libitum diet was not affected by treatment (table 2). Dietary fiber intakes without the fiber treatment were similar to the average total fiber intake in 
Table 2. Summary of the subjects' ad libitum diets during the treatment periods

\begin{tabular}{|c|c|c|c|c|c|c|}
\hline & Pullulan & $\begin{array}{l}\text { Resistant } \\
\text { Starch }\end{array}$ & $\begin{array}{l}\text { Soluble } \\
\text { fiber dextrin }\end{array}$ & $\begin{array}{l}\text { Soluble } \\
\text { Corn Fiber }\end{array}$ & $\begin{array}{l}10-\mathrm{DE} \\
\text { maltodextrin }\end{array}$ & $\mathrm{p}$ value \\
\hline Energy, kcal & $2,186 \pm 109$ & $2,318 \pm 160$ & $2,140 \pm 104$ & $2,197 \pm 136$ & $2,195 \pm 126$ & 0.8025 \\
\hline Total carbohydrate, g & $266 \pm 16$ & $277 \pm 25$ & $250 \pm 12$ & $267 \pm 24$ & $272 \pm 18$ & 0.8259 \\
\hline Protein, $g$ & $81 \pm 4$ & $88 \pm 5$ & $82 \pm 5$ & $83 \pm 5$ & $84 \pm 5$ & 0.7686 \\
\hline Total fat, $g$ & $84 \pm 4$ & $90 \pm 6$ & $88 \pm 5$ & $90 \pm 6$ & $84 \pm 6$ & 0.7947 \\
\hline Total cholesterol, mg & $245 \pm 19$ & $294 \pm 27$ & $261 \pm 26$ & $331 \pm 40$ & $236 \pm 21$ & 0.0549 \\
\hline Total fiber, $g$ & $29 \pm 1^{a}$ & $30 \pm 1^{\mathrm{a}}$ & $29 \pm 1^{\mathrm{a}}$ & $29 \pm 1^{\mathrm{a}}$ & $18 \pm 1^{b}$ & $<0.001$ \\
\hline Soluble fiber, $g$ & $17 \pm 0.5^{\mathrm{a}}$ & $5 \pm 0.5^{\mathrm{b}}$ & $17 \pm 0.5^{\mathrm{a}}$ & $17 \pm 0.5^{\mathrm{a}}$ & $5 \pm 0.5^{\mathrm{b}}$ & $<0.001$ \\
\hline Insoluble fiber, $\mathrm{g}$ & $12 \pm 1^{\mathrm{a}}$ & $25 \pm 1^{\mathrm{b}}$ & $12 \pm 1^{\mathrm{a}}$ & $12 \pm 1^{\mathrm{a}}$ & $13 \pm 1^{\mathrm{a}}$ & $<0.001$ \\
\hline
\end{tabular}

Values reported as adjusted means \pm SEM. Data collected during the last 3 days of treatment via a 3-day food record. Total fiber, soluble fiber and insoluble fiber intake includes fiber present in the ad libitum diet plus the fiber treatment or placebo. $p$ values represent differences between treatments, adjusted for visit. Within a row, treatments with different letters were significantly different.

Table 3. Subjective markers of laxation

\begin{tabular}{|c|c|c|c|c|c|c|}
\hline & Pullulan & $\begin{array}{l}\text { Resistant } \\
\text { Starch }\end{array}$ & $\begin{array}{l}\text { Soluble } \\
\text { fiber dextrin }\end{array}$ & $\begin{array}{l}\text { Soluble } \\
\text { Corn Fiber }\end{array}$ & $\begin{array}{l}\text { 10-DE malto- } \\
\text { dextrin (placebo) }\end{array}$ & $\mathrm{p}$ value ${ }^{2}$ \\
\hline \multicolumn{7}{|l|}{ Gastrointestinal symptoms ${ }^{1}$} \\
\hline Bloating & $3.9 \pm 0.4^{\mathrm{a}}$ & $2.8 \pm 0.4^{\mathrm{b}}$ & $2.8 \pm 0.4^{b}$ & $3.1 \pm 0.4^{\mathrm{a}, \mathrm{b}}$ & $2.2 \pm 0.3^{b}$ & 0.0040 \\
\hline Cramping & $2.8 \pm 0.4^{\mathrm{a}}$ & $2.3 \pm 0.4^{\mathrm{a}, \mathrm{b}}$ & $2.0 \pm 0.3^{\mathrm{a}, \mathrm{b}}$ & $1.8 \pm 0.3^{\mathrm{b}}$ & $1.5 \pm 0.2^{\mathrm{b}}$ & 0.0269 \\
\hline Flatulence & $5.1 \pm 0.4^{\mathrm{a}}$ & $3.9 \pm 0.4^{\mathrm{b}}$ & $4.0 \pm 0.4^{\mathrm{b}}$ & $4.2 \pm 0.4^{\mathrm{b}}$ & $2.8 \pm 0.3^{c}$ & $<0.0001$ \\
\hline Stomach noises & $3.4 \pm 0.4^{\mathrm{a}}$ & $3.2 \pm 0.4^{\mathrm{a}}$ & $2.6 \pm 0.3^{\mathrm{a}, \mathrm{b}}$ & $2.9 \pm 0.3^{\mathrm{a}}$ & $2.0 \pm 0.2^{b}$ & 0.0075 \\
\hline GI score & $3.8 \pm 0.4^{\mathrm{a}}$ & $3.0 \pm 0.4^{\mathrm{a}, \mathrm{b}}$ & $2.8 \pm 0.4^{\mathrm{b}, \mathrm{c}}$ & $3.0 \pm 0.4^{b}$ & $2.1 \pm 0.2^{c}$ & 0.0036 \\
\hline Stool consistency (self-reported) ${ }^{1}$ & $2.1 \pm 0.1$ & $2.2 \pm 0.1$ & $2.1 \pm 0.1$ & $2.0 \pm 0.1$ & $2.2 \pm 0.1$ & 0.6715 \\
\hline Stool consistency (investigator-reported) & $2.5 \pm 0.2$ & $2.4 \pm 0.2$ & $2.5 \pm 0.2$ & $2.3 \pm 0.2$ & $2.5 \pm 0.2$ & 0.4333 \\
\hline
\end{tabular}

Values reported as treatment means \pm SEM, adjusted for visit. Symptoms were each rated on a 10 -point scale $(1=$ minimal, $10=$ excessive). The GI score is the mean of bloating, cramping, flatulence and stomach noise ratings (possible range 1-10). Selfreported stool consistency was rated on a 10 -point scale $(1=$ diarrhea, $10=$ hard). The scale was adjusted to a 4 -point scale to coincide with investigator-reported stool consistency Investigator- reported stool consistency was rated on a scale from 1 to $4: 1=$ hard and formed, 2 = soft and formed, 3 = loose and unformed, $4=$ liquid [9]. $p$ values represent differences between treatments. Treatments with different letters are significantly different.

${ }^{1}$ Data from day 3 and day 14 did not differ significantly, so the days were pooled for analysis. the USA. The fiber treatment increased total fiber intake to 29-30 g/day. GI symptoms did not differ between day 3 and day 14, so data were pooled for analysis. Bloating, cramping, flatulence, stomach noises and GI score were significantly affected by treatment, with all fibers inducing a modest increase in GI symptoms compared to the control (table 3). Overall, the mean symptom scores were low (1.8-5.1), indicating that the GI symptoms from the fibers were minimal. Stool $\mathrm{pH}$ was significantly affected by treatment with soluble fiber dextrin, which produced the lowest fecal pH (table 4). None of the treatments were significantly different to control. The $\mathrm{pH}$ measurements did not reflect the SCFA concentrations present in the stool (table 4). Total SCFAs did not differ among treatments. Resistant Starch produced the lowest propionate percentage. The percentages of acetate and butyrate in the stool samples did not differ between the treatments.

The number of stools per day and self-reported stool consistency did not differ between days 3 and 14, so data were pooled for analysis. These outcomes did not differ 
Table 4. Objective markers of laxation

\begin{tabular}{|c|c|c|c|c|c|c|}
\hline & Pullulan & $\begin{array}{l}\text { Resistant } \\
\text { Starch }\end{array}$ & $\begin{array}{l}\text { Soluble } \\
\text { fiber dextrin }\end{array}$ & $\begin{array}{l}\text { Soluble } \\
\text { Corn Fiber }\end{array}$ & $\begin{array}{l}\text { 10-DE malto- } \\
\text { dextrin (placebo) }\end{array}$ & $\mathrm{p}$ value \\
\hline Number of stools per day (self-reported) ${ }^{1}$ & $1.2 \pm 0.1$ & $1.3 \pm 0.1$ & $1.2 \pm 0.1$ & $1.2 \pm 0.1$ & $1.2 \pm 0.1$ & 0.8866 \\
\hline Number of stools in 4 days & $3.4 \pm 0.4$ & $4.0 \pm 0.4$ & $3.6 \pm 0.4$ & $3.7 \pm 0.4$ & $3.6 \pm 0.3$ & 0.4787 \\
\hline Individual stool weight, $\mathrm{g} / \mathrm{stool}$ & $174 \pm 16$ & $142 \pm 12$ & $155 \pm 14$ & $150 \pm 14$ & $161 \pm 16$ & 0.1273 \\
\hline Total stool output in 4 days, $g$ & $614 \pm 105$ & $588 \pm 78$ & $595 \pm 99$ & $546 \pm 80$ & $571 \pm 73$ & 0.8425 \\
\hline Stool $\mathrm{pH}$ & $6.27 \pm 0.06^{\mathrm{a}, \mathrm{b}}$ & $6.35 \pm 0.07^{\mathrm{a}}$ & $6.11 \pm 0.08^{\mathrm{b}}$ & $6.40 \pm 0.07^{\mathrm{a}}$ & $6.28 \pm 0.07^{\mathrm{a}, \mathrm{b}}$ & 0.0376 \\
\hline Total SCFA concentration, $\mu \mathrm{mol} / \mathrm{g}$ stool & $156 \pm 9$ & $137 \pm 9$ & $160 \pm 13$ & $162 \pm 12$ & $144 \pm 7$ & 0.1876 \\
\hline Acetate, $\%$ & $40.9 \pm 1.0$ & $43.6 \pm 1.1$ & $43.8 \pm 0.9$ & $42.9 \pm 0.9$ & $42.8 \pm 0.9$ & 0.1444 \\
\hline Propionate, \% & $26.3 \pm 0.9^{\mathrm{a}}$ & $23.1 \pm 0.8^{\mathrm{b}}$ & $25.0 \pm 0.9^{\mathrm{a}}$ & $25.7 \pm 1.0^{\mathrm{a}}$ & $25.1 \pm 0.8^{\mathrm{a}}$ & 0.0059 \\
\hline Butyrate, \% & $32.8 \pm 1.4$ & $33.3 \pm 1.4$ & $31.1 \pm 1.4$ & $31.4 \pm 0.8$ & $32.0 \pm 1.3$ & 0.6076 \\
\hline
\end{tabular}

Values reported as treatment means \pm SEM, adjusted for visit. p values represent differences between treatments. Treatments with different letters are significantly different.

${ }^{1}$ Data from day 3 and day 14 did not differ significantly, so the days were pooled for analysis.

Table 5. Summary of fasting blood measurements, blood pressure and body weight

\begin{tabular}{|c|c|c|c|c|c|c|}
\hline & Pullulan & $\begin{array}{l}\text { Resistant } \\
\text { Starch }\end{array}$ & $\begin{array}{l}\text { Soluble } \\
\text { fiber dextrin }\end{array}$ & $\begin{array}{l}\text { Soluble } \\
\text { Corn Fiber }\end{array}$ & $\begin{array}{l}\text { 10-DE malto- } \\
\text { dextrin (placebo) }\end{array}$ & $\mathrm{p}$ value \\
\hline Total triglycerides, mg/dl & $90 \pm 11$ & $95 \pm 11$ & $103 \pm 12$ & $91 \pm 12$ & $91 \pm 13$ & 0.3778 \\
\hline Total cholesterol, mg/dl & $168 \pm 7$ & $70 \pm 8$ & $170 \pm 7$ & $169 \pm 7$ & $163 \pm 7$ & 0.2439 \\
\hline LDL cholesterol, mg/dl & $98 \pm 6$ & $99 \pm 6$ & $100 \pm 6$ & $99 \pm 6$ & $94 \pm 6$ & 0.2370 \\
\hline HDL cholesterol, mg/dl & $52 \pm 3$ & $52 \pm 2$ & $50 \pm 2$ & $52 \pm 3$ & $50 \pm 2$ & 0.3169 \\
\hline Glucose, $\mathrm{mg} / \mathrm{dl}$ & $94 \pm 2$ & $93 \pm 2$ & $94 \pm 1$ & $89 \pm 5$ & $93 \pm 1$ & 0.3484 \\
\hline Insulin, $\mu \mathrm{IU} / \mathrm{ml}$ & $4.7 \pm 1.1$ & $4.8 \pm 1.2$ & $5.8 \pm 1.7$ & $5.7 \pm 1.5^{1}$ & $4.0 \pm 1.1$ & 0.2976 \\
\hline C-reactive protein, $\mathrm{mg} / \mathrm{l}$ & $1.7 \pm 0.4^{2}$ & $1.1 \pm 0.3$ & $1.2 \pm 0.4$ & $1.1 \pm 0.2$ & $1.0 \pm 0.3$ & 0.5359 \\
\hline Ghrelin $^{3}, \mathrm{pg} / \mathrm{ml}$ & $1,014 \pm 113$ & $958 \pm 86$ & $885 \pm 88$ & $1,018 \pm 71$ & $969 \pm 95$ & 0.1959 \\
\hline Blood pressure (systolic/diastolic), $\mathrm{mm} \mathrm{Hg}$ & $121 / 67 \pm 2 / 2$ & $118 / 65 \pm 3 / 2$ & $121 / 69 \pm 3 / 2$ & $119 / 68 \pm 2 / 2$ & $116 / 67 \pm 2 / 2$ & $0.2647 / 0.2273$ \\
\hline Body weight, $\mathrm{kg}$ & $73.8 \pm 2.0$ & $72.0 \pm 1.8$ & $71.9 \pm 1.9$ & $71.8 \pm 1.8$ & $71.7 \pm 1.8$ & 0.2062 \\
\hline
\end{tabular}

Values are reported as treatment means \pm SEM. p values represents differences between treatments, adjusted for visit.

${ }^{1} \mathrm{n}=19$ due to missing data.

${ }^{2} \mathrm{n}=18$ due to outliers. Two subject values were removed due to illness.

${ }^{3}$ In 7 instances, ghrelin concentrations fell below the detection limit and were not included in the analysis (pullulan, $\mathrm{n}=19 ; \mathrm{Resistant}$ Starch, $\mathrm{n}=18$; soluble fiber dextrin, $\mathrm{n}=19$; Soluble Corn Fiber, $\mathrm{n}=19 ; 10$-DE maltodextrin, $\mathrm{n}=18$ ).

among treatments (tables 3,4$)$. The number of stools collected in 4 days, stool weight, total stool output in 4 days and investigator-evaluated stool consistency did not differ among treatments (table 3). The investigator-evaluated stool consistency coincided with the self-reported stool consistency and number of stools collected in 4 days (table 3).

Mean fasting total triglyceride concentrations after fiber treatments or placebo ranged from 90 to $103 \mathrm{mg} / \mathrm{dl}$, but the differences among means were not statistically significant. Treatment means for fasting total cholesterol, LDL cholesterol and HDL cholesterol did not differ among the treatments and ranged from 160 to $170 \mathrm{mg} / \mathrm{dl}$, from 94 to $100 \mathrm{mg} / \mathrm{dl}$ and from 50 to $52 \mathrm{mg} / \mathrm{dl}$, respectively (table 5).

Fasting glucose and insulin concentrations did not differ among treatments, and all fell within the nondiabetic range $(<125 \mathrm{mg} / \mathrm{dl}$ glucose, $<17 \mu \mathrm{IU} / \mathrm{ml}$ insulin; table 5). One insulin sample was not available for analysis from the Soluble Corn Fiber treatment due to improper 
Table 6. Self-reported hunger prior to meals

\begin{tabular}{|c|c|c|c|c|c|c|}
\hline & Pullulan & $\begin{array}{l}\text { Resistant } \\
\text { Starch }\end{array}$ & $\begin{array}{l}\text { Soluble } \\
\text { fiber dextrin }\end{array}$ & $\begin{array}{l}\text { Soluble } \\
\text { Corn Fiber }\end{array}$ & $\begin{array}{l}\text { 10-DE malto- } \\
\text { dextrin (placebo) }\end{array}$ & $\mathrm{p}$ value \\
\hline \multicolumn{7}{|l|}{ Day 3} \\
\hline Breakfast & $4.6 \pm 0.5$ & $4.7 \pm 0.5$ & $4.9 \pm 0.5$ & $3.7 \pm 0.4$ & $4.5 \pm 0.5$ & 0.2216 \\
\hline Lunch & $5.7 \pm 0.3$ & $5.1 \pm 0.3$ & $5.2 \pm 0.3$ & $5.4 \pm 0.3$ & $5.1 \pm 0.3$ & 0.5532 \\
\hline Dinner & $5.7 \pm 0.4$ & $6.0 \pm 0.4$ & $5.8 \pm 0.4$ & $5.4 \pm 0.4$ & $5.8 \pm 0.4$ & 0.7938 \\
\hline \multicolumn{7}{|l|}{ Day 14} \\
\hline Breakfast & $4.6 \pm 0.5$ & $3.9 \pm 0.6$ & $4.5 \pm 0.5$ & $4.3 \pm 0.5$ & $4.7 \pm 0.5$ & 0.6975 \\
\hline Lunch & $5.5 \pm 0.4$ & $5.5 \pm 0.5$ & $5.2 \pm 0.4$ & $5.6 \pm 0.4$ & $5.9 \pm 0.4$ & 0.7311 \\
\hline Dinner & $5.5 \pm 0.4$ & $5.3 \pm 0.4$ & $5.7 \pm 0.4$ & $5.2 \pm 0.4$ & $5.9 \pm 0.4$ & 0.7022 \\
\hline
\end{tabular}

Values reported as adjusted means \pm SEM. Subjects were instructed to rate their state of hunger prior to breakfast, lunch and dinner on days 3 and 14 of the treatment period. The ratings were based on a 10-point scale $(1=$ no desire to eat, $10=$ unbearable hunger, must eat immediately). p values represents differences between treatments, adjusted for visit.

sample handling. C-reactive protein concentrations did not change with treatment and fell within the 'average risk for cardiovascular disease' range of $1.0-3.0 \mathrm{mg} / \mathrm{l}$ for all treatments. Two C-reactive protein values (both from different subjects on pullulan treatment) were omitted from analysis due to reported illness. Mean ghrelin concentrations did not differ with treatment (table 5). Mean systolic blood pressure was nearly ideal $(<120 \mathrm{~mm} \mathrm{Hg})$, and mean diastolic blood pressure fell within the ideal range ( $<80 \mathrm{~mm} \mathrm{Hg}$; table 5$)$. No changes in body weight were reported with treatment (table 5).

Hunger prior to breakfast, lunch and dinner on days 3 and 14 did not differ among treatments (table 6). Subjects reported being slightly hungrier before breakfast on day 3 (ratings 3.7-4.9) and day 14 (ratings 3.9-4.7) than before lunch or dinner (range 5.1-6.0).

\section{Discussion}

We gave our subjects $12 \mathrm{~g}$ per day of different fibers, a palatable amount representing the usual gap in dietary fiber intake in the USA. Despite this increase in fiber intake, few changes in laxative effect were found. There was no change in stool output, weight or consistency with treatment, but it should be noted that all subjects had normal stool weights at the start of the study and were not constipated. This modest amount of fiber was well tolerated by the subjects, and the study fibers could easily be added to low-fiber foods.

The present study was designed as a placebo-controlled, crossover study, and statistical analyses were planned according to this design. Each fiber treatment was compared to the placebo to determine a treatment effect. Subjects often behave differently while enrolled in a clinical trial. Using a placebo as opposed to baseline measurement takes into account any differences as a result of being a study participant, but without an increase in fiber consumption. As such, baseline data, aside from anthropometric measurements (data not shown), were not collected.

The type of fiber can influence fecal output and characteristics in humans. A randomized crossover experiment with practical doses of isolated fibers (14-15 g/day psyllium, guar gum or xanthan gum) showed that each fiber had a different effect on fecal output and the response was highly individualized [12]. The effect of RS on fecal output has been mixed and may depend on the physicochemical properties of the specific RSs. High doses of wheat dextrin (up to $80 \mathrm{~g} /$ day) had only a minimal effect on fecal output [13], while another study with lower doses of RS2 and RS3 (30 g/day) showed that both altered fecal weight in healthy humans [14]. Retrograded maltodextrin (40-60 g/day) administered for 21 days produced an increase in total bowel movements and frequency of watery feces [15]. Fecal output was increased by the addition of 17-30 g/day RS from a variety of sources (banana, wheat, potato and maize) [16]. A low dose of konjac glucomannan (4.5 g/day) significantly increased the number of bowel movements per day as well as daily fecal wet weight [17]. This illustrates that the laxative effect of fiber cannot be generalized across all types of fiber or even generalized within a specific class of fiber, and the fiber dose for increased laxation is dependent on the fiber type. 
One mechanism by which dietary fiber is thought to alter stool weight and consistency is by fermentation of the fiber to SCFAs. SCFA concentrations after the treatments used in this study did not differ from control. Since the majority of SCFAs ( $>90 \%)$ are rapidly absorbed from the lumen [18], excreted SCFA concentrations provide only an estimate of actual SCFA production. Mean stool $\mathrm{pH}$ did not reflect the total SCFA concentrations, which may be due to the presence of other anionic compounds (succinate, lactate, bicarbonate) in the stool. SCFA production shifts from butyrate to acetate and propionate as colonic pH increases (5.5-6.5) [19]. The observed change in $\mathrm{pH}$ was not reflected in the percentages of acetate, propionate and butyrate recovered in the stool. The $\mathrm{pH}$ change may have been too small to produce a measurable difference in SCFA production. Other studies with RS have shown a change in SCFA and fecal pH. However, these studies administered doses ranging from 30 to 50 $\mathrm{g} /$ day [20-22]. A larger sample size and more specific fermentation metabolite analysis may be required to see a relationship between $\mathrm{pH}$ and SCFA concentration.

The addition of $12 \mathrm{~g} /$ day fiber to the diet represented a significant increase in daily fiber intake for the subjects. Fiber intake in female subjects was slightly over the recommended levels, while male subjects, even with the supplementation, still consumed approximately $8 \mathrm{~g} /$ day fiber less than the Dietary Reference Intake (DRI) fiber recommendation.

GI symptoms ratings with fiber supplementation were mild to moderate in our study. RS is well tolerated in humans, even in high doses (45-60 g/day) $[15,20,22,23]$. RS doses above $60 \mathrm{~g} /$ day produced greater flatulence, $\mathrm{ab}$ dominal distension and abdominal cramping compared to control treatments in previous reports [13, 24, 25]. Similar to the current study, administration of $10.33 \mathrm{~g} /$ day RS3 for 7 days did not affect flatulence [26]. The high tolerance of RS in the present study was expected due to the low daily dose (12 g/day). Gas production (flatulence and distention) after pullulan administration has been reported previously and was significantly higher when subjects consumed $50 \mathrm{~g}$ of high-molecular weight pullulan (molecular weight 100,000) compared to control [27].

Lipid values with all treatments fell near or within the recommended ranges for triglycerides $(<150 \mathrm{mg} / \mathrm{dl})$, total cholesterol $(<200 \mathrm{mg} / \mathrm{dl})$, LDL cholesterol $(<100 \mathrm{mg} / \mathrm{dl})$ and HDL cholesterol (>40 mg/dl) [28]. RS, when incorporated into foods or consumed as a supplement, has inconsistent effects on cholesterol and triglyceride concentrations $[14,22,29,30]$. All of the studies reporting decreased triglycerides required the subjects to consume controlled meals with RS, which may have improved compliance. Typically, viscous, soluble fibers are most likely to lower total serum cholesterol and LDL cholesterol.

Most studies with RS see no change in fasting glucose or fasting insulin [22, 30-32] after chronic RS intake; however, a recent study with obese women showed that $40 \mathrm{~g}$ of RS administered for 21 days decreased fasting glucose [33]. Pullulan decreased the postprandial glucose response in humans compared to a digestible control (maltodextrin) [34].

Ghrelin is a gut hormone that signals satiety. The majority of data on ghrelin and dietary fiber are postprandial data. The present study showed no effect of chronic fiber intake on fasting ghrelin concentrations. Previous studies have reported mixed effects of fiber on fasting ghrelin concentrations [35, 36]. Standard fasting ghrelin concentrations have not been established, so it is not possible to categorize subjects as 'normal' or 'out of range'. In the present study, hunger before meals did not differ with the fiber treatments.

\section{Conclusion}

Pullulan, Resistant Starch, soluble fiber dextrin and Soluble Corn Fiber consumed in a practical dose (12 g/ day) were well tolerated in humans and did not significantly alter laxation or serum markers of coronary heart disease, diabetes or satiety. Further research should be focused on populations with poor colon health, poor laxation or a high risk of chronic disease to fully understand the therapeutic effects of these fibers.

\section{Acknowledgments}

This study was supported by the National Center for Research Resources, National Institutes of Health (grant M01-RR00400), Tate and Lyle Inc. (Health and Nutrition Sciences, Decatur, Ill., USA) and the University of Minnesota (St. Paul, Minn., USA).

\footnotetext{
References $\quad 1$ Lembo A, Camilleri M: Chronic constipation. N Engl J Med 2003;349:1360-1368.

2 Queenan KM, Stewart ML, Smith KN, Thomas W, Fulcher RG, Slavin JL: Concentrated oat beta-glucan, a fermentable fiber, lowers serum cholesterol in hypercholesterolemic adults in a randomized controlled trial. Nutr J 2007;6:6
} 
3 Variyam JN: Factors affecting the macronutrient intake of US adults. Washington, United States Department of Agriculture, 2003, Technical Bulletin 1901.

4 Institute of Medicine: Dietary Reference Intakes for Energy, Carbohydrates, Fiber, Fat, Fatty Acids, Cholesterol, Protein, and Amino Acids. Washington, National Academies Press, 2005

5 McNeil NI: The contribution of the large intestine to energy supplies in man. Am J Clin Nutr 1984;39:338-342.

6 Flood MT, Auerbach MH, Craig SAS: A review of the clinical toleration studies of polydextrose in food. Food Chem Toxicol 2004; 42:1531-1542.

7 Livesey G: Tolerance of low-digestible carbohydrates: a general view. Br J Nutr 2001;85: S7-S16.

8 Stewart ML, Slavin JL: Novel maize-based dietary fibers have comparable in vitro fermentability to inulin and partially-hydrolyzed guar gum. FASEB J 2007;21:368.7.

$\checkmark 9$ Whelan K, Judd PA, Taylor MA: Assessment of faecal output in patients receiving enteral tube feeding: validation of a novel chart. Eur J Clin Nutr 2004;58:130-137.

-10 Schneider SM, Girard-Pipau F, Anty R, van der Linde EGM, Philipsen-Geerling BJ, Knol J, Filippi J, Arab K, Hebuterne X: Effects of total enteral nutrition supplemented with a multi-fibre mix on faecal short-chain fatty acids and microbiota. Clin Nutr 2006;25:8290.

11 Geleva D, Thomas W, Gannon MC, Keenan JM: A solubilized cellulose fiber decreases peak postprandial cholecystokinin concentrations after a liquid mixed meal in hypercholesterolemic men and women. J Nutr 2003;133:2194-2203.

12 Tomlin J, Read NW: The relation between bacterial degradation of viscous polysaccharides and stool output in human beings. Br J Nutr 1988:60:467-475.

13 van den Heuvel EG, Wils D, Pasman WJ, Bakker M, Saniez MH, Kardinaal AF: Shortterm digestive tolerance of different doses of NUTRIOSE FB, a food dextrin, in adult men. Eur J Clin Nutr 2004;58:1046-1055.

- 14 Jenkins DJ, Vuksan V, Kendall CW, Wursch $P$, Jeffcoat R, Waring S, Mehling CC, Vidgen E, Augustin LS, Wong E: Physiological effects of resistant starches on fecal bulk, short chain fatty acids, blood lipids and glycemic index. J Am Coll Nutr 1998;17:609-616.

15 Storey D, Lee A, Bornet F, Brouns F: Gastrointestinal responses following acute and medium term intake of retrograded resistant maltodextrins, classified as type 3 resistant starch. Eur J Clin Nutr 2007;61:1262-1270.
16 Cummings JH, Beatty ER, Kingman SM, Bingham SA, Englyst HA: Digestion and physiological properties of resistant starch in the human large bowel. Br J Nutr 1996;75: 733-747.

17 Chen HL, Cheng HC, Liu YJ, Liu SY, Wu WT: Konjac acts as a natural laxative by increasing stool bulk and improving colonic ecology in healthy adults. Nutrition 2006;22: 1112-1119.

18 Macfarlane GT, Gibson GT: Microbiology in the large bowel; in Cummings JH, Rombeau JL, Sakata T (eds): Physiological and Clinical Aspects of Short-Chain Fatty Acids. New York, Cambridge University Press, 1995.

19 Walker AW, Duncan SH, McWilliam Leitch EC, Child MW, Flint HJ: pH and peptide supply can radically alter bacterial populations and short-chain fatty acid ratios within microbial communities from the human colon. Appl Environ Microbiol 2005;71:36923700.

20 Christl SU, Katzenmaier U, Hylla S, Kasper $\mathrm{H}$, Scheppach W: In vitro fermentation of high-amylose cornstarch by a mixed population of colonic bacteria. JPEN J Parenter Enteral Nutr 1997;21:290-295.

21 Phillips J, Muir JG, Birkett A, Lu ZX, Jones GP, O’Dea K, Young GP: Effect of resistant starch on fecal bulk and fermentation-dependent events in humans. Am J Clin Nutr 1995;62:121-130.

22 Pasman W, Wils D, Saniez MH, Kardinaal A: Long-term gastrointestinal tolerance of NUTRIOSE FB in healthy men. Eur J Clin Nutr 2006;60:1024-1034.

23 Hylla S, Gostner A, Dusel G, Anger H, Bartram HP, Christl SU, Kasper H, Scheppach $\mathrm{W}$ : Effects of resistant starch on the colon in healthy volunteers: possible implications for cancer prevention. Am J Clin Nutr 1998;67: 136-142.

24 Muir JG, Lu ZX, Young GP, Cameron-Smith D, Collier GR, O’Dea K: Resistant starch in the diet increases breath hydrogen and serum acetate in human subjects. Am J Clin Nutr 1995;61:792-799.

$\checkmark 25$ Vermorel M, Coudray C, Wils D, Sinaud S, Tressol JC, Montaurier C, Vernet J, Brandolini M, Bouteloup-Demange C, Rayssiguier Y: Energy value of a low-digestible carbohydrate, NUTRIOSE FB, and its impact on magnesium, calcium and zinc apparent absorption and retention in healthy young men. Eur J Nutr 2004;43:344-352.

26 Tomlin J, Read NW: The effect of resistant starch on colon function in humans. Br J Nutr 1990;64:589-595.
27 Spears JK, Karr-Lilienthal LK, Bauer LL, Murphy MR, Fahey GC Jr: In vitro fermentation characteristics of selected glucose-based polymers by canine and human fecal bacteria. Arch Anim Nutr 2007;61:61-73.

28 National Cholesterol Education Program, National Heart, Lung, and Blood Institute, National Institutes of Health: Third Report of the National Cholesterol Education Program (NCEP) Expert Panel on Detection, Evaluation, and Treatment of High Blood Cholesterol in Adults (Adult Treatment Panel III). NIH Publication No. 02-5215. Bethesda, National Heart, Lung, and Blood Institute, 2002.

29 Behall KM, Howe JC: Effect of long-term consumption of amylose vs. amylopectin starch on metabolic variables in human subjects. Am J Clin Nutr 1995;61:334-340.

30 Behall KM, Scholfield DJ, Yuhaniak I, Canary J: Diets containing high amylose vs. amylopectin starch: effects on metabolic variables in human subjects. Am J Clin Nutr 1989;49:337-344.

31 Noakes M, Clifton PM, Nestel PJ, Le Leu R, McIntosh G: Effect of high-amylose starch and oat bran on metabolic variables and bowel function in subjects with hypertriglyceridemia. Am J Clin Nutr 1996;64:944951.

$>32$ Higgins JA, Higbee DR, Donahoo WT, Brown IL, Bell ML, Bessesen DH: Resistant starch consumption promotes lipid oxidation. Nutr Metab (Lond) 2004;1:8.

33 Park OJ, Kang NE, Chang MJ, Kim WK: Resistant starch supplementation influences blood lipid concentrations and glucose control in overweight subjects. J Nutr Sci Vitaminol (Tokyo) 2004;50:93-99.

34 Wolf BW, Garleb KA, Choe YS, Humphrey PM, Maki KC: Pullulan is a slowly digested carbohydrate in humans. J Nutr 2003;133: 1151-1155.

35 Garcia AL, Otto B, Reich SC, Weickert MO, Steiniger J, Machowetz A, Rudovich NN, Mohlig M, Katz N, Speth M, Meuser F, Doerfer J, Zunft HJ, Pfeiffer AH, Koebnick C: Arabinoxylan consumption decreases postprandial serum glucose, serum insulin and plasma total ghrelin response in subjects with impaired glucose tolerance. Eur J Clin Nutr 2007;61:334-341.

36 Robertson MD, Bickerton AS, Dennis AL, Vidal H, Frayn KN: Insulin-sensitizing effects of dietary resistant starch and effects on skeletal muscle and adipose tissue metabolism. Am J Clin Nutr 2005;82:559-567. 